\title{
John Hamilton Travelling Fellowship
}

The John Hamilton Travelling Fellowship is awarded from funds bequeathed by Dr John Hamilton, past Honorary Secretary of the Forensic Section and College Fellow.

Dr John Hamilton trained and worked in Edinburgh before he took up a post as Senior Lecturer in Forensic Psychiatry at the Maudsley and Consultant Forensic Psychiatrist at Broadmoor Hospital. He later went on to become Medical Director of Broadmoor Hospital before his untimely death. He visited Russia as a representative of the College and was particularly keen on the development of forensic psychiatry services in other countries.

The intention of this travelling fellowship is to encourage psychiatrists working in the field of forensic psychiatry to broaden their knowledge and experience through travel to recognised forensic centres. Proposals to visit forensic services which are developing in order to support, advise and teach will be considered. Although not essential, candidates may wish to pursue a research topic or a comparative study.

(1) Applicants must have their MRCPsych and be either on an approved higher training scheme in forensic psychiatry, or hold a consultant forensic psychiatrist post.
(2) Applicants must work in the UK or Ireland.

(3) Application forms are available from the Postgraduate Education Department. The forms should be supported by:

(i) the names of two referees

(ii) a detailed proposal as to how the time abroad will be spent

(iii) information about the host centre, with confirmation that the proposal is acceptable to them

(iv) an identified supervisor at the host centre.

(4) The successful candidate will be expected to submit a report to the Chairman of the Forensic Section.

(5) The Fellowship will be awarded on a biennial basis.

(6) The Fellowship will be awarded by a panel consisting of the Dean and two forensic psychiatry assessors nominated by the Chairman of the Forensic Psychiatry Section.

(7) The value of the Fellowship is $\$ 2,000$ and entries for the Prize should be submitted to the Dean by 30 September 1995.

\section{Membership of Transcultural Special Interest Group}

The Transcultural Special Interest Group was formed as a result of a broad church consensus that the needs of the black and ethnic minority groups living in Britain today needed to have their needs met. It was important that psychiatrists should lead this debate and a group was formed within the College. The membership of the Group is broad church in that it has representatives from all the different disciplines within the College and from psychiatrists irrespective of their cultural origins. The TSIG officers wish to draw this to the attention of all readers and potential members as there appears to be a misunderstanding that membership of TSIG is restricted to psychiatrists from ethnic minority groups. This is not the case.

\section{The Library and Information Service}

During the summer period the College Library will be closed from 14 August to 1 September 1995. 